\title{
An efficient, cost-effective and simple solution
}

Stabilok Dentine Pin system from Fairfax Dental offers a highly efficient and cost-effective way of ensuring the stability of restorations.

The system essentially provides a contra-angle shank on which restorative material can be built,
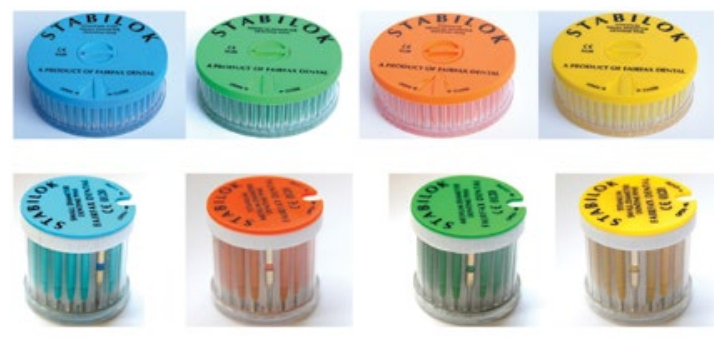

regardless of whether you're using

amalgam or composite. The kit includes a twist-drill for preparation of the dentine, which carefully controls the depth of cut by automatically shearing off the pin when the correct depth is reached. This ensures maximum accuracy and a firmly anchored restoration that lasts.

A highly accessible, affordable and simple solution, the Stabilok Dentine Pin system from

Fairfax Dental is ideal for patients or professionals who wish to avoid more invasive alternative treatments.

Now available directly from the manufacturer for even greater quality assurance, discover the Stabilok Dentine Pin system from Fairfax Dental today.

For more information, contact 02089476464.

\section{The independent agency you can trust}

The approach of the agency that you choose can make all the difference to the outcome of your practice sale or acquisition. For an independent agency that constantly strives to challenge the market to provide a fair and balanced service that is beneficial to all, contact Dental Elite.

As well as having a proactive, forwardthinking attitude, Dental Elite offers a transparent and fair fee structure, open bidding process and detailed impartial valuation complete with the methodology to demonstrate the results. This ensures that both vendors and buyers achieve the best outcome possible.

And if that doesn't convince you, perhaps the agency's 4.7 out of 5 customer rating will. Don't delay - call today!

For more information on Dental Elite visit www.dentalelite.co.uk, email info@ dentalelite.co.uk or call 01788545900.

\section{Complete care for your compressed air}

When you have a compressed air system in your practice, it's your responsibility to ensure that it remains safe and compliant.

But when balancing this alongside treating patients and running your business, it can be hard to find the time. So why not get someone else to do it for you?

Total Air Care from DentalAir is an innovative idea that takes care of all maintenance and compliance of your air compressor for a fixed monthly cost. Available from just $£ 19.50$ per month, DentalAir will fit you with a new silenced oil-free air compressor that supplies sterile air, as well as provide annual maintenance, a PSSR written scheme of examination (required in the BDA good practice guide), yearly air quality tests and a swift backup support service should anything ever go wrong.

All you need to do is pay the monthly fee and leave DentalAir to worry about the rest, giving you the time to concentrate on treating your patients and running the other aspects of your business.

For more information, contact DentalAir at info@dentalair.com or call 08009757530 .

\section{A breakthrough in the detection of active demineralisation}

CALCIVIS is the innovative UK biologic and device manufacturer behind the revolutionary CALCIVIS imaging system. This technology represents a breakthrough in the detection of active demineralisation and significant progress for caries disease prevention. Using bioluminescence, the CALCIVIS imaging system detects free calcium ions as they are released from actively demineralising tooth surfaces. This information is captured and a visual map of active demineralisation is generated at the chair side.

The evidence-based CALCIVIS images enable dental professionals to initiate first response treatment at the very early stages of the disease process - offering patients the best possible preventive dental care.
For more information visit www.calcivis. com, call on 01316585152 or email info@

calcivis.com. All claims relate to and are approved for the UK dental market.

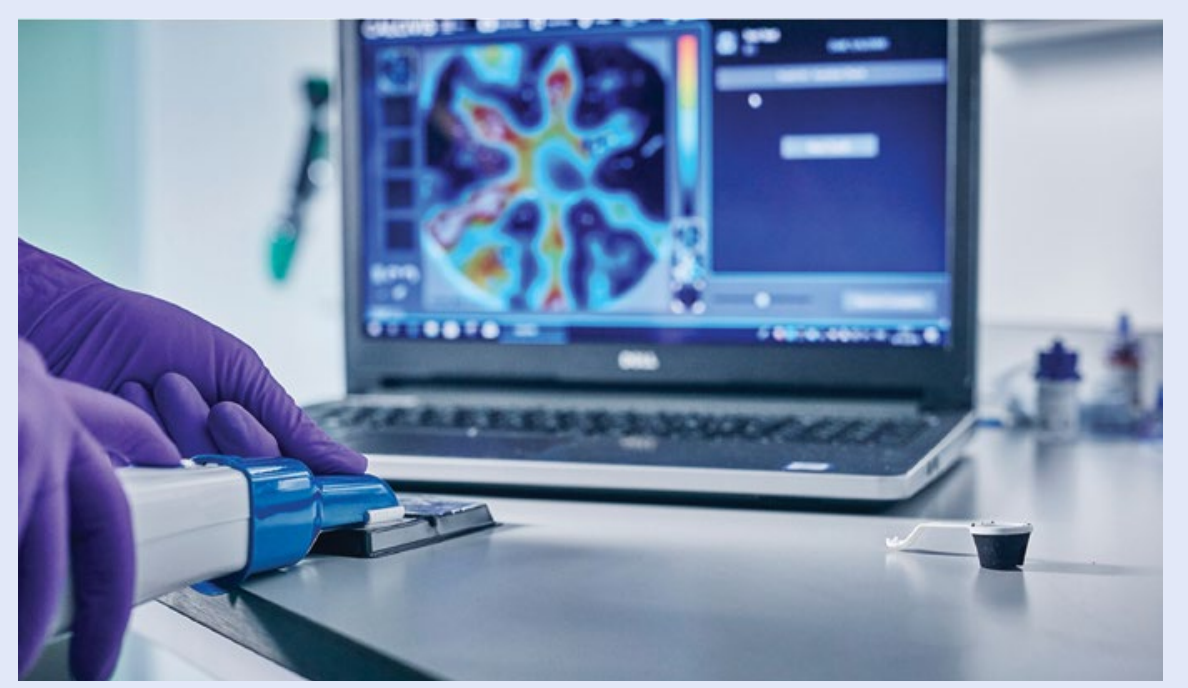

